\title{
Social self-value intervention for empowerment of HIV infected people using antiretroviral treatment: a randomized controlled trial
}

Dharma Nand Bhatta ${ }^{1,2^{*}}$ and Tippawan Liabsuetrakul ${ }^{2}$

\begin{abstract}
Background: Prevention and antiretroviral therapy (ART) management for human immunodeficiency virus (HIV) infected people need to have long-term health care. An empowerment focused intervention is a procedure by which HIV infected people obtain combined possession of programs to attain mainly cost-effective HIV outcomes and deal with social and structural difficulties related to their universal health access and human rights. Empowerment is a key approach for addressing HIV related issues that focuses on addressing a broader context. However, the practices of empowerment based approaches are sparse. We assessed the effect of an intervention to empower HIV infected people receiving ART.
\end{abstract}

Methods: In this open-label randomized controlled trial, HIV infected people from Nepal who were using ART from 6 to 24 months and were aged 18 years and above were randomly assigned to receive either the intervention or routine care. The intervention was led by two counselors for a period lasting six weeks. Participants were followed up at three and six months after the baseline. The primary outcome was change in empowerment scores, analyzed by using Difference-in-Difference (DiD).

Results: Between September and November 2014, 1447 HIV infected people were screened, of whom 132 were randomly assigned to the intervention $(n=66)$ or control $(n=66)$ group. All the participants completed the $3-$ and 6- months follow up. A significant difference in mean empowerment score was found between the groups at 3(46.77, $p$-value <0.001) and 6- (49.71, p-value <0.001) months follow up. The average treatment effect (after matching intervention and control individuals) showed that the participants who received the intervention increased their mean empowerment scores from baseline by 47.05 ( $p$-value $<0.001$, at three months) and 49.87 ( $p$-value $<0.001$, at six months) than those who did not receive the intervention. No adverse events were reported.

Conclusion: Social self-value intervention provided to HIV infected people during ART increased their empowerment. This intervention can be expanded to be utilized in routine services.

Trial registration: Thai Clinical Trials Registry, number TCTR20140814002.

Keywords: Adherence, ART, Disclosure, Self-esteem, Unprotected sexual intercourse

\footnotetext{
* Correspondence: dnbhatta@yahoo.com

${ }^{1}$ Department of Public Health, Pokhara University, Nobel College, Kathmandu,

Nepal

${ }^{2}$ Faculty of Medicine, Epidemiology Unit, Prince of Songkla University,

Songkhla, Thailand
} 


\section{Background}

Morbidity and mortality due to human immunodeficiency virus (HIV) infections can be reduced by preventing new HIV infections [1-3]. Globally, an estimated two million people were newly HIV infected in 2014 [4]. Viral load status of HIV in HIV positive people and risky sexual behavior with HIV uninfected people is the first and foremost way of transmission of HIV [5]. HIV transmission could be potentially reduced through interventions given at every step of the HIV care continuum including an efficient diagnosis system, adherence to medical care, suppression of viral load, and quality of antiretroviral treatment $[6,7]$. Continuous intervention of medical care, treatment, counseling and screening might help to reduce HIV transmissions [8-10]. Persons who are HIV positive but ignorant of their HIV status have more risk behaviors of HIV transmission than those who were conscious of their infection [11, 12]. Reduction of HIV transmission is associated with antiretroviral treatment (ART) and maintaining a high retention rate in medical treatment is essential to gaining access to ART and suppression of HIV viral load [8, 9, 13].

Universal access to treatment for those who need ART is very low $[4,14]$. In addition, antiretroviral drug toxicity, resistance and non infectious developments are the major challenges for maintaining a higher retention rate in regular medical care [15-17]. Furthermore, low negotiation skills of risky sexual behavior with sexual partners, social problems, co-infections and re-infections make HIV infected people more vulnerable [18, 19]. Existing studies of HIV interventions and non-interventions have focused on primary and secondary prevention of subgroups and clinical implications for mortality and morbidity rather than the possible outcome for HIV prevention among all HIV infected people $[6,7,20-24]$. Moreover, overambitious targets related to HIV including zero new infections, discrimination and stigma have been established by various agencies [25-27]. However, gold standard interventions have been unable to address those targets. An empowerment approach would be an asset to achieve above HIV related inequalities and targets [28-31]. While health outcomes and self care behaviors are linked to empowerment methods with a supportive social environment, it must be considered for implementation in programs and policies to increase epidemiological profits on investment $[32,33]$.

An empowerment approach has not yet been developed and tested for all HIV infected people. Empowerment is a cost-effective approach to reduce HIV transmission, improve treatment retention, and reduce social, physical and psychological problems $[34,35]$. This social self-value intervention package was developed on the basis of the diffusion model of innovations study [36]. The concept of social action and empowerment theories were used to enhance self-efficacy, self-care, family and social relationships, stigma and discrimination issues [37-41] which are the major obstacles among HIV populations. As a result, self-esteem, autonomy, social adaptation or relationship and behavior change for structural prevention as an empowerment framework could be strengthened [20-24, 42, 43]. We aimed to assess the effect of this intervention on empowerment of HIV infected people receiving ART.

\section{Methods}

\section{Study design, settings and participants}

This open label, parallel, randomized controlled trial was conducted in Kathmandu, Nepal. HIV infected participants receiving antiretroviral treatment (ART) from ART centers of Kathmandu district of Nepal were recruited. The study was conducted from September 2014 to June 2015. The study site was Sukraraj Tropical and Infectious Disease Hospital (STIDH), Teku, Kathmandu run by the government of Nepal and was a part of the National Center for AIDS and STD Control (NCASC) [44]. This site is the largest ART center catering to both rural and urban people living in Nepal. It has provided multidisciplinary clinical and laboratory services and treatment for HIV infected people since 2004 [45]. Figure 1 shows details of the study design and participant enrollment.

Eligible participants included HIV infected people aged 18 years or above, willing to participate in either intervention or control arm, and had been receiving ART between 6 and 24 months prior to the study according to the ART criteria as per the guidelines of NCASC [46]. We excluded participants who were exposed to similar educational programs or any other intervention, expressed inability to attend all the study follow up periods, suffering from health problems (psychotic disorders, visual and hearing problems), and unwilling to disclose their HIV status among other participants.

A total sample size of 132 participants (66 in the control arm and 66 in the intervention arm) would achieve $80 \%$ power to detect a significant mean difference of empowerment scores at a level of 0.05. Since, no previously published study was found for the mean change of intervention $\left(\mu_{1}-\mu_{2}\right)$, a $20 \%$ mean difference was applied which was equal to 0.52 standard deviation $(\sigma)$. The formula for testing the difference between two means (two-sample $t$-test) was used to arrive at the sample size.

\section{Randomization and masking}

Participants were randomly allocated to either the intervention or control arm with a ratio of 1:1. Randomization was performed by a random number generator with permuted blocks of six. Allocation concealment was done by using sequentially numbered opaque sealed envelopes. The independent data manager generated the randomly sequence numbers. The 


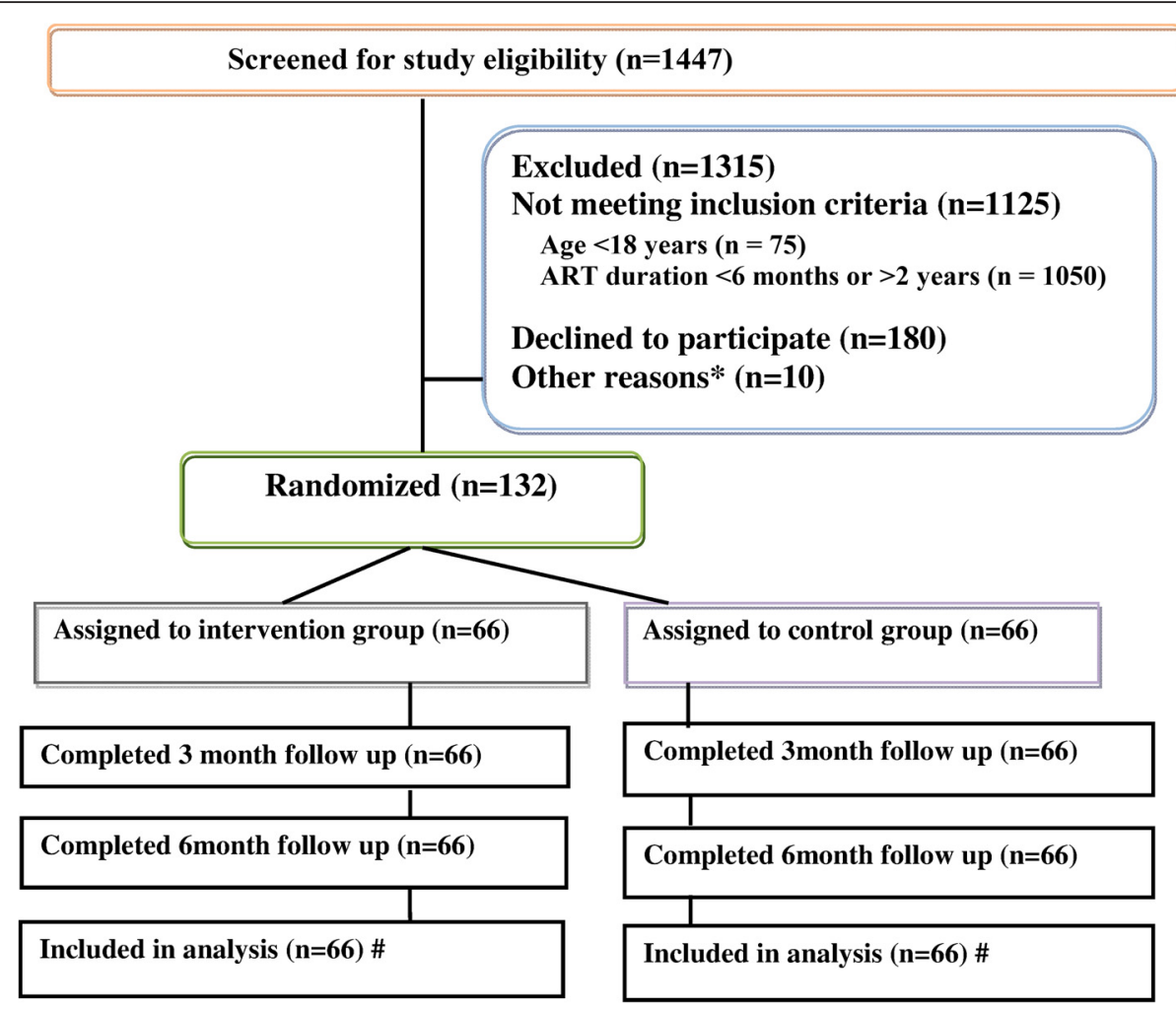

Fig. 1 Study design and participant enrolment flow diagram. Legend: *Patients transferred out or did not come to the center during recruitment period. \#intention-to-treat design

sequence numbers were masked from other research staff and participants. None of the research team members and participants was involved in the randomization process and subsequent to randomization none of the participants were able to modify their assignment. Enumerator and analysis assessor were masked from baseline to follow-up data by using a unique code. The unique code was developed for all the participants by the team leader to maintain the anonymity of the participants.

\section{Intervention procedures}

Many theories were followed to develop the intervention package. The intervention contents were developed based on social learning, social action, and pedagogy theory and empowerment principles for HIV prevention and treatment [20-24, 37-43].

All the participants completed a baseline survey before the intervention began. Once participants were recruited and assigned their allocation baseline characteristics were collected.

All participants who met the selection criteria were informed about the study process, design and goals. All subjects in the intervention group attended six intervention sessions of one and half hours duration at the ART center. Intervention sessions were conducted once per week and per session eight to ten participants were included. All the sessions were led by two national level trainers with public health degrees. The intervention sessions were as follows: first session covered rapport building, sharing uncomfortable situations and management of negativity; second session started with barriers and strategies of HIV disclosure and defeat with stigma and self-esteem; third session covered healthy body and healthy mind, healthy sexual relations, means to be HIV infected or non-infected to be a man or woman, sexuality, adherence of ART and other treatment and prevention strategies after infection; fourth session started with strategies to plan for healthy relations with family members, the community and society, effective communication, and responsibilities in the society; fifth session discussed negative effects of illicit drugs, alcohol, and smoking, skills for co-infection, re-infection and partner's sexual behavior, diet and exercise; sixth session educated about legal empowerment, human rights, legal protection, discrimination, stress, rising voice together against discrimination and rights and future goals.

Acceptability, applicability and relevancy of the intervention contents were discussed with two experts, three HIV infected people and two counselors. After necessary amendment, the contents for all six sessions were pre- 
tested among ten HIV infected people. Participatory learning activities, buzz sessions, brain storming, lecturers, and discussion techniques were used in the intervention sessions. Participants were instructed to discuss the issues within their group and other participants. Participants were encouraged to communicate with their family members, peer groups, friends related to HIV control, prevention, treatment and disclosure. Participants were assigned home assignments at the end of each session for presentation at the next session. All the participants in the intervention group were compensated for each of their six sessions with an amount equivalent to US \$ 20 in the local currency. The control group did not receive any compensation.

Fidelity of the intervention was maintained with continuous monitoring of the allocated time for topics, methods and contents of the sessions by health officers and the research team leader. In addition, anonymity was maintained with a code and participants were assured quality during the discussion sessions. To maintain compliance, at the end of the each session the counselors motivated participants to participate in the next session, encouraged voluntary independent participation and provided gift vouchers. The overall participant retention rate was $96.6 \%$ in the intervention session.

\section{Standard care}

All participants received routine standard care as per the NCASC guidelines [46]. This included pre ART counseling, routine medical and laboratory tests and monthly follow up for ART. Standard care in Nepal is provided by government organizations and ART is dispensed free of cost.

\section{Study procedures}

Participants were asked to provide information on demographics, empowerment and behaviors at baseline and follow up (first follow up: 3 months after the baseline and second follow up: 3 months after the first follow up). To minimize the errors and enhance quality control, double data entry was employed and extensively supervised by the research team leader. Anonymity and confidentiality were maintained with assigned unique codes. Intervention contents and tools were pre-tested before baseline and follow up data collection.

\section{Measures}

Demographic characteristics included age, sex, ethnicity, religion, occupation, education, marital status, children and per capita family income.

The primary outcome was measured by using an empowerment scale developed by Rogers et al. [47], containing a total of 28 items each measured on a four-point agreement scale ranging from strongly disagree to strongly agree.
Total empowerment scores ranged from 28 to 112 consisting of five subscales, namely self-efficacy/self-esteem (9-36 score), power-powerlessness (7-28 score), community activism and autonomy (5-20 score), optimism and control over the future (4-16 score) and righteous anger (3-12 score). First, the contents of the questionnaire were discussed with two experts who amended the language for suitability with HIV patients. Further contents were revised to be applicable to the Nepalese culture and contexts. The content was then discussed with three HIV infected people for clarity and acceptance, and amended accordingly. After development of the revised version with experts and HIV infected people, the final version was pretested among HIV infected people. During the pre-test, no negative comments or difficulties were encountered by participants. Internal consistency, as measured by Cronbach's alpha was 0.97 .

disclosure of HIV status (coded as yes or no, if response was yes then the number of persons disclosed was recorded and dichotomized as $\leq 3$ persons or $>3$ persons). These secondary outcomes were measured to assess the effect of empowerment to patient's behaviors which were important to their health outcomes.

\section{Statistical analyses}

Demographic characteristics were compared between the intervention and control group at baseline. Baseline differences between the two groups were tested using Fisher's exact or Chi-squared test for categorical variables and unpaired t-tests or Wilcoxon's signed rank test for continuous variables as appropriate.

Analysis of the primary outcome emphasized the differences of empowerment scores among HIV infected people comparing between the intervention and control groups at baseline (baseline difference or pre-difference) and at 3- (post-difference at 3 months) and 6- month post-intervention (post-difference at 6 months). The impact of the intervention on empowerment was analyzed by comparing Difference-in-Differences (DiD) scores. The impact of the intervention was measured between baseline difference and post difference at 3 months $\left(\mathrm{DiD}_{3 \mathrm{mo}}\right)$ and between baseline difference and post difference at 6 months $\left(\mathrm{DiD}_{6 \mathrm{mo}}\right)$. The secondary outcomes were analyzed at baseline, 3- and 6- months follow up using univariate analysis. Significant differences among intervention and control were measure using Fisher's exact test.

\section{Difference in Differences (DiD)}

DiD methods can be used to estimate causal relationships [48]. DiD compare the differences in outcomes among the intervention group in pre- and post-intervention and involves indentifying similar differences among the control group. We used DiD to compare outcomes between control and intervention groups at baseline, 3- and 6- months 
follow up [49]. Ordinary Least Square (OLS) with repeated data for control and intervention group for baseline, 3and 6- month follow up periods produced standard errors and DiD estimates. The equation considered as follows:

$$
\mathrm{Y}_{\text {ist }}=\mathrm{A}_{\mathrm{s}}+\mathrm{B}_{\mathrm{t}}+\mathrm{cX} \mathrm{X}_{\text {ist }}+\beta \mathrm{I}_{\mathrm{st}}+\mathrm{e}_{\text {ist }}
$$

where empowerment is the outcome of interest, denoted as $Y_{i s t}$ for the individual of HIV infected $i$ in randomized group $s$ (control or intervention) by time $t$ (the baseline and 3- or 6- months follow up) and $I_{s t}$ is an indicator variable representing whether the intervention has affected the group $s$ at time $t . A_{s}$ and $B_{t}$ are fixed effects for the randomized group and time (baseline and follow up) respectively, $X_{i s t}$ are applicable individual controls and $e_{\text {ist }}$ is the error term. The impact of the intervention was estimated by OLS with $\beta$ estimation. Means and standard errors were estimated by linear regression. Following linear regression for the individual $i$ :

$$
\begin{aligned}
\text { Outcome }_{i}= & \beta_{\mathrm{o}}+\beta_{1} \times \text { period }_{\mathrm{i}}+\beta_{2} \times \text { treated }_{\mathrm{i}} \\
& +\beta_{3} \times \text { period }_{\mathrm{i}} \times \text { treated }_{\mathrm{i}}+\mathrm{e}_{\mathrm{i}}
\end{aligned}
$$

where, ${ }^{\wedge} \beta_{3}$ : is the $\mathrm{DiD}$ or impact.

The analyses were done with $\mathrm{R}$ and Stata (diff command) was used for estimating the DiD [50]. All tests were two sided and a $p$-value of $<0.05$ indicated statistical significance.

\section{Ethical considerations}

Comprehensive privacy was maintained during the study period. Strict anonymity and confidentiality was maintained throughout the recruitment, intervention and data collection process by using unique codes. A standard protocol was followed to maintain data safety and confidentiality of the study data [51]. In agreement with national guidelines and the principles of the declarations of Helsinki, written informed consent was obtained from all participants prior to enrollment. The right to withdraw at any time and skip any question was offered to all participants. We provided travel costs and reimbursement during the intervention and follow up periods. Researchers had no direct or financial benefits and declared no conflict of interest.

This project was approved by the Research Ethics Committee, Faculty of Medicine, Prince of Songkla University, Thailand (reference no. 57-0146-18-5) and approved by Institutional Ethical Review Committee of Sukraraj Tropical and Infectious Disease Hospital (STIDH), Nepal (063/071/72) prior to study initiation. The trial was registered through trial registration number TCTR20140814002 (www.clinicaltrials.in.th). All the contents were reported as per the CONSORT guidelines.

\section{Results}

A detail of the trial profile is shown in Fig. 1. One hundred thirty-two participants were randomly assigned to receive the intervention $(n=66)$ or no intervention $(n=66)$ between September and November 2014. 1447 individuals were screened and of these, 1125 were ineligible, 180 declined to participate and 10 were excluded due to being transferred out or because they did not come to the center during the recruitment period. All participants in both groups were retained in the study at three and six months follow-up (100\% retention rate).

No significant differences at baseline were observed in demographic characteristics of the participants between the intervention and control groups. The mean ages of participants in the intervention and control groups were 36.3 and 35.8 years, respectively. The majority had a low family income, was married and had children (Table 1).

The correlations among empowerment domains and total empowerment score are presented in Fig. 2. Total scores of empowerment were positively correlated with the other five domains at baseline, 3- and 6- months follow up. In the intervention group at the 6 months follow up, power-powerlessness, community activism and autonomy, optimism and control over the future were negatively correlated with righteous anger, and were lowly correlated with self-efficacy/self-esteem and righteous anger.

The impact of the intervention on empowerment is presented in Table 2. The baseline difference (pre-difference) of empowerment scores between the intervention and control groups were not significantly different. Difference-in-Difference at 3- $(46.77, p<0.001)$ and 6months $(49.71, p<0.001)$ were significantly higher for the intervention group in all domains of empowerment.

After standardization of scores for each domain, the impact of the intervention on each domain of empowerment remained equal. Participants who received the intervention increased their empowerment scores by an average of 47.05 points ( $p$-value $<0.001, \mathrm{DiD}$ at three months and baseline) and 49.87 points ( $p$-value $<0.001$, $\mathrm{DiD}$ at six months and baseline) more than those who did not receive the intervention, after propensity score matching of intervention and control individuals (data not shown).

Figure 3 depicts the trend of average empowerment scores among the two groups at baseline, 3- and 6months follow up. The mean post-intervention score of empowerment markedly increased among the intervention group at 3 months but only slightly increased at 6 months, while the mean score for the control group remained constant.

Table 3 shows pre- and post-intervention differences on behavioral and clinical characteristics. From baseline to 6 months, unprotected sexual intercourse with any 
Table 1 Baseline demographic characteristics

\begin{tabular}{|c|c|c|c|}
\hline & $\begin{array}{l}\text { Control } \\
\text { group }\end{array}$ & $\begin{array}{l}\text { Intervention } \\
\text { group }\end{array}$ & $\begin{array}{l}p \text { - } \\
\text { value }\end{array}$ \\
\hline & $(n=66)$ & $(n=66)$ & \\
\hline \multicolumn{4}{|l|}{ Age (years) } \\
\hline Mean(SD) & $35.8(8.8)$ & $36.3(6.8)$ & 0.71 \\
\hline$\leq 36$ & $36(54.5)$ & $41(62.1)$ & \multirow[t]{2}{*}{0.48} \\
\hline$>36$ & $30(45.5)$ & $25(37.9)$ & \\
\hline \multicolumn{3}{|l|}{ Gender } & \multirow[t]{3}{*}{0.22} \\
\hline Female & $39(59.1)$ & $31(47)$ & \\
\hline Male & $27(40.9)$ & $35(53)$ & \\
\hline \multicolumn{3}{|l|}{ Ethnicity } & \multirow[t]{3}{*}{0.60} \\
\hline Indigenous & $31(47.0)$ & $27(40.9)$ & \\
\hline Non-indigenous & $35(53.0)$ & $39(59.1)$ & \\
\hline \multicolumn{3}{|l|}{ Religion } & \multirow[t]{3}{*}{0.44} \\
\hline Hindu & $49(74.2)$ & $44(66.7)$ & \\
\hline Others & $17(25.8)$ & $22(33.3)$ & \\
\hline \multicolumn{3}{|l|}{ Occupation } & \multirow[t]{4}{*}{0.85} \\
\hline Unemployed & $22(33.3)$ & $21(31.8)$ & \\
\hline Informal employee & $25(37.9)$ & $23(34.8)$ & \\
\hline Formal employee & $19(28.8)$ & $22(33.3)$ & \\
\hline \multicolumn{3}{|l|}{ Education level } & \multirow[t]{3}{*}{0.10} \\
\hline Illiterate informal & $29(43.9)$ & $19(28.8)$ & \\
\hline Primary and above & $37(56.1)$ & $47(71.2)$ & \\
\hline \multicolumn{3}{|l|}{ Marital status } & \multirow[t]{3}{*}{0.10} \\
\hline Single & $17(25.8)$ & $17(25.8)$ & \\
\hline Married & $49(74.2)$ & $49(74.2)$ & \\
\hline \multicolumn{3}{|l|}{ Children } & \multirow[t]{3}{*}{0.09} \\
\hline No & $14(21.2)$ & $6(9.1)$ & \\
\hline Yes & $52(78.8)$ & $60(90.9)$ & \\
\hline \multicolumn{3}{|l|}{ Number of children } & \multirow[t]{3}{*}{0.08} \\
\hline$\leq 2$ & $39(59.1)$ & $50(75.8)$ & \\
\hline$>2$ & $13(19.7)$ & $10(15.2)$ & \\
\hline \multicolumn{4}{|c|}{$\begin{array}{l}\text { Family per-capita income } \\
\left(U_{S D^{a}}\right)\end{array}$} \\
\hline Median(IQR) & $50(30.67)$ & $50(30.67)$ & 0.81 \\
\hline$\leq 50$ & $41(62.1)$ & $44(66.7)$ & 0.72 \\
\hline$>50$ & $25(37.9)$ & $22(33.3)$ & \\
\hline
\end{tabular}

${ }^{a} 1$ USD 100NPR, IQR inter quartile range, $S D$ standard deviation

partner decreased in the intervention group and increased in the control group. The proportion of those who ever forgot to take ART did not change in the intervention group but the proportion rose from baseline to 6 months among the control group. No participant forgot to take ART in the past week in the intervention group. The proportion of participants who disclosed their HIV status rose from baseline to 6 months in the intervention group. Focusing on change from baseline to
6 months, statistically significant differences between the control and intervention groups were found for unprotected sexual intercourse $(p$-value $<0.001)$, forgetting to ever take ART ( $p$-value 0.007 ), forgetting to take ART in the past week ( $p$-value $<0.001)$, and disclosure of HIV status $(p$-value $<0.001)$.

\section{Discussion}

A social self-value intervention package was shown to empower HIV infected people receiving ART and improved their behaviors. Our study highlighted a significantly greater increase in empowerment for HIV infected people at 3and 6- months from the baseline. Similar findings were highlighted by a quasi-experimental study from Canada that anticipated empowering HIV infected people [52]. However, there are sparse existing studies available related to empowerment of all HIV infected people $[52,53]$.

Baseline characteristics of the participants were not statistically significant different among the intervention and control groups. Further we collected background characteristics (age, sex, ethnicity, marital status, date ART started) for all the screened participants. There was no difference in these background characteristics between those who agreed to participate in the study and those who refused thus minimizing biological, environmental and socioeconomic bias. The given reasons for refusal to participate were lack of interest, time and perceived need for the intervention. The strong recruitment process enhanced a higher retention rate in the intervention group and lower loss to follow up at 3- and 6months. The intervention sessions took place in the same center where the controls received ART. This could have increased the chance of contamination among the control group. To reduce this risk, we conducted the intervention after services had finished for the day in each center and participants were counseled not to disclose any activities during the study period. The fact that the findings did not show any changes among the control group after the intervention provides evidence of no or minimal contamination. On the other hand, provided incentives to the intervention group could lead to confirmation bias. Incentivized group might be more biased in their information than who did not get incentives.

The total empowerment score was highly correlated with its different domains but different domains were loaded with various correlations from high (self-efficacy) to low (righteous anger). Self-efficacy/self-esteem domain revealed a significant enhancement at six months which was similar to findings from previous studies using different interventions for HIV infected populations [52, 54, 55]. It was confirmed in a systematic review on community-based interventions that empowerment intervention had positive effects on self-esteem [56]. Self-esteem is necessary to 


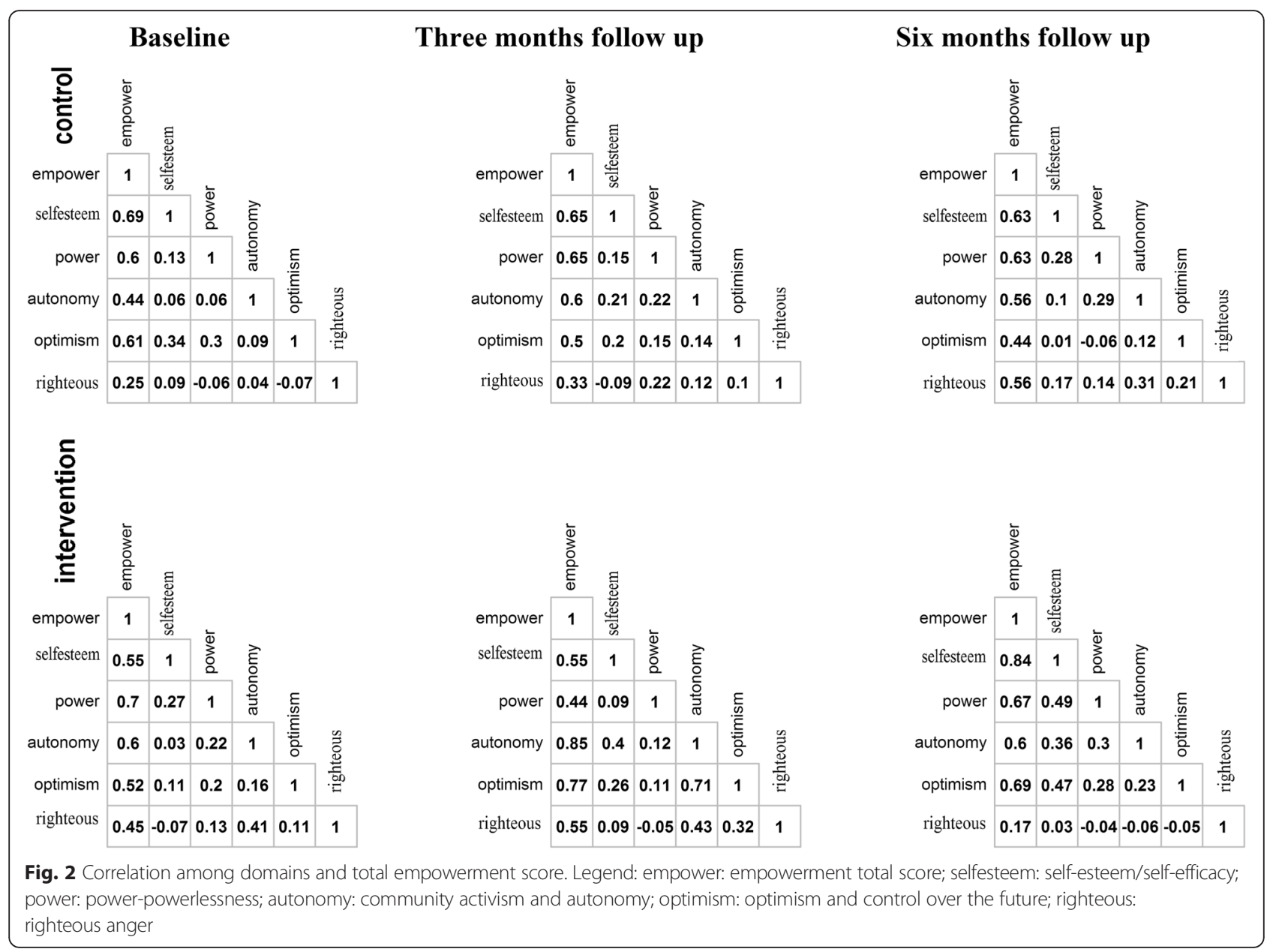

enhance the management of the negative social, physical and emotional impacts of HIV infection, thus our intervention was useful to support these issues.

Righteous anger domain was negatively correlated with the other domains. This might be the effect of the intervention that operates to reduce feelings of revenge over perceived mistreatment among HIV infected people. In addition, greatly increased righteous anger (reactive feeling of fury over abuse) scores had a positive influence on social and community adaption and adjustment of HIV infected people. Our trial showed a significantly greater increase in community activism and autonomy, power-powerlessness

Table 2 Impact of intervention on empowerment

\begin{tabular}{|c|c|c|c|c|c|c|c|c|c|c|c|}
\hline & \multicolumn{2}{|l|}{ Baseline } & \multicolumn{2}{|c|}{3 month follow up } & \multirow{2}{*}{$\begin{array}{l}\text { Pre- } \\
\text { Diff }\end{array}$} & \multirow{2}{*}{$\begin{array}{l}\text { Post- } \\
\text { Diff }\end{array}$} & \multirow{2}{*}{$\begin{array}{l}\mathrm{DiD}_{3 \mathrm{mo}^{*}} \\
\text { (Impact) }\end{array}$} & \multicolumn{2}{|c|}{6 month follow up } & \multirow{2}{*}{$\begin{array}{l}\text { Post- } \\
\text { Diff }\end{array}$} & \multirow{2}{*}{$\begin{array}{l}\mathrm{DiD}_{6 \mathrm{mo}}{ }^{*} \\
\text { (Impact) }\end{array}$} \\
\hline & Control & Intervention & Control & Intervention & & & & Control & Intervention & & \\
\hline Empowerment (total score) & 46.70 & 46.38 & 48.23 & 94.68 & -0.32 & 46.45 & 46.77 & 46.53 & 95.92 & 49.39 & 49.71 \\
\hline Self-efficacy/self-esteem & 15.27 & 15.03 & 15.39 & 30.33 & -0.24 & 14.94 & 15.18 & 15.12 & 30.91 & 14.79 & 16.03 \\
\hline Power-powerlessness & 12.00 & 12.03 & 12.26 & 23.92 & 0.03 & 11.67 & 11.64 & 11.67 & 24.18 & 12.51 & 12.48 \\
\hline $\begin{array}{l}\text { Community activism and } \\
\text { autonomy }\end{array}$ & 8.01 & 8.04 & 8.65 & 16.83 & 0.03 & 8.18 & 8.15 & 8.26 & 16.92 & 8.67 & 8.64 \\
\hline $\begin{array}{l}\text { Optimism and control over } \\
\text { the future }\end{array}$ & 6.59 & 6.50 & 6.61 & 13.54 & -0.09 & 6.94 & 7.03 & 6.36 & 13.41 & 7.04 & 7.14 \\
\hline Righteous anger & 4.82 & 4.77 & 5.32 & 10.04 & -0.04 & 4.73 & 4.77 & 5.12 & 10.50 & 5.38 & 5.42 \\
\hline
\end{tabular}

${ }^{*}=p<0.001$; Pre-diff difference at baseline, Post-diff ${ }_{3 m o}$ difference at 3 month follow up, Post-diff ${ }_{6 m o}$ difference at 6 month follow up, DiD ${ }_{3 m o}$ difference at baseline and 3 month follow up, $D i D_{6 m o}$ difference at baseline and 6 month follow up 


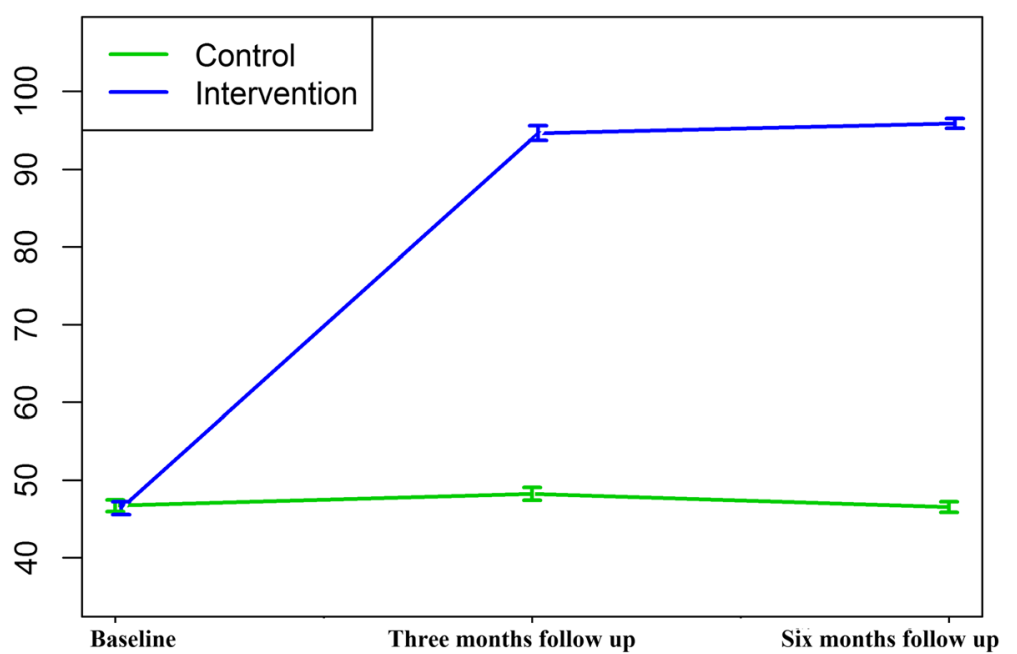

Fig. 3 Trend of average empowerment score with $95 \%$ confidence interval for intervention and control groups

(helpless and totally incompetent) and optimism and control over the future (hope and assurance about the future or successful result of something). This may have affected the capacity to rebalance and reincorporate their lives [57]. HIV infection might guide the person to the destruction of their life goals, as well as absence of autonomy and selfcontrol. Powerlessness and lack of control over the future appears as a diverse risk factor of disease. The impact of the intervention was further validated by using an average treatment effect model with propensity score matching. This was done to reduce the bias, although the participants were randomly assigned and no significant changes were reported after the modeling. Findings revealed significant improvements in empowerment score from baseline to
3 months follow up, but only minimal improvements at six months. The improvements at three months might be due to the immediate effect of the intervention while lack of further improvements at 6 months is probably due to a ceiling effect - the optimum empowerment score may have already been achieved. However, this needs long-term follow up to illicit the possible effects and reasons.

Our intervention improved not only empowerment but also the behavior of HIV infected people most likely because behavior related contents were included in the intervention package. A systematic review of interventions showed both significant and non-significant positive effects of interventions to reduce risk behaviors [58]. Our study found that the practice of unprotected sexual

Table 3 Pre- and post-intervention differences on behavioral and clinical characteristics

\begin{tabular}{|c|c|c|c|c|c|c|c|c|c|}
\hline & \multicolumn{3}{|l|}{ Baseline } & \multicolumn{3}{|c|}{ Three month follow up } & \multicolumn{3}{|c|}{ Six month follow up } \\
\hline & $\begin{array}{l}\text { Control } \\
(n=66)\end{array}$ & $\begin{array}{l}\text { Intervention } \\
(n=66)\end{array}$ & $P$-value & $\begin{array}{l}\text { Control } \\
(n=66)\end{array}$ & $\begin{array}{l}\text { Intervention } \\
(n=66)\end{array}$ & $P$-value & $\begin{array}{l}\text { Control } \\
(n=66)\end{array}$ & $\begin{array}{l}\text { Intervention } \\
(n=66)\end{array}$ & $P$-value \\
\hline $\begin{array}{l}\text { Unprotected sexual intercourse with } \\
\text { any partner in last } 3 \text { months }{ }^{a}\end{array}$ & & & 0.82 & & & 0.001 & & & 0.001 \\
\hline No & $38(76.0)$ & $36(72.0)$ & & $19(35.8)$ & $47(100.0)$ & & $19(36.5)$ & $45(95.7)$ & \\
\hline Yes & $12(24.0)$ & $14(28.0)$ & & $34(64.2)$ & $0(0)$ & & $33(63.5)$ & $2(4.3)$ & \\
\hline Ever forgot to take ART & & & 0.16 & & & 0.38 & & & 0.007 \\
\hline Yes & $23(34.8)$ & $32(48.5)$ & & $26(39.4)$ & $32(48.5)$ & & $48(72.7)$ & $32(48.5)$ & \\
\hline No & $43(65.2)$ & $34(51.5)$ & & $40(60.6)$ & $34(51.5)$ & & $18(27.3)$ & $34(51.5)$ & \\
\hline Forgot to take ART in past week & & & 0.78 & & & 0.001 & & & 0.001 \\
\hline Yes & $6(9.1)$ & $8(12.1)$ & & $56(84.8)$ & $0(0)$ & & $20(30.3)$ & $0(0)$ & \\
\hline No & $60(90.9)$ & $58(87.9)$ & & $10(15.2)$ & $66(100.0)$ & & $46(69.7)$ & $66(100.0)$ & \\
\hline Disclosure of HIV status with ${ }^{b}$ & & & 0.93 & & & 0.001 & & & 0.001 \\
\hline$\leq 3$ persons & $46(80.7)$ & $45(77.6)$ & & $46(76.7)$ & $18(27.3)$ & & $44(73.3)$ & $2(3.0)$ & \\
\hline$>3$ persons & 11 (19.3) & $13(22.4)$ & & $14(23.3)$ & $48(72.7)$ & & $16(26.7)$ & $64(97.0)$ & \\
\hline
\end{tabular}

${ }^{\mathrm{a}}$ Missing data ${ }^{\mathrm{b}}$ among disclosed, $p$-value $=$ Fisher's exact test 
intercourse among HIV infected people with any partner was significantly reduced after the intervention. A systematic review on community empowerment interventions for HIV prevention showed a reduction in risky sexual behaviors and increase in condom use among sex workers [59]. Another study related to empowerment of young HIV infected people showed a significant improvement in protected sexual intercourse [55]. This trial revealed a significant improvement in adherence to ART among the intervention group and a decrease among the control group. Previous interventions highlighted that the empowerment of HIV infected people showed an improvement in adherence to ART $[52,60]$. Our study highlighted a significant increase in HIV status disclosure rate. Disclosure is important to prevent the spread of HIV, increase the wisdom of selfesteem, emotional and practical support from social networks [61]. An empowerment intervention was envisioned with a multi-level construct that entails an understanding of social adaptation or relationship, self-esteem, autonomy, and behavior change for structural prevention throughout the contribution of developed skills, strengths and advocacy to behavioral, social interdependence and cognitive changes. This outcome might be the path of effect that is associated with empowerment theory.

Studies related to empowerment to all the HIV infected people were not available in this region. Although applicable to local culture and context intervention package, a highly experienced interventionist and extensive quality control measure might be the reason for improvement of empowerment scores and behavioral outcomes among the intervention group. Although subgroup analysis was found significant in small sample size and we suggested evaluating in future multicenter and large sample size based intervention and long term effects. An empowerment measurement tool would yield two dimensions of self and community directions to empowerment. Community orientation to empowerment believed that HIV infected people have power inside the society and desire to encourage community action in an unfriendly world. Self orientations to empowerment believe themselves to be self-esteem, self-efficacious, and optimistic to the future.

\section{Strengths and limitations}

This trial was based on randomly assigned participants, a blinded analysis process and use of rigorous outcome analysis guaranteeing high internal validity. The intervention package and measurement tools were pre-tested in different stages which increased its reliability. The intervention package was found acceptable and feasible after measurement by both qualitative and quantitative approaches [62]. A high retention rate in the intervention group as well as during follow up was maintained.
The intervention was conducted in the regular health care service setting provided by the Nepalese government which pretend the real world setting and added to the external validity. Our study population characteristics including socio-demographic and clinical features were consistent with other HIV infected populations in Nepal. Therefore, the results can be generalizable to other HIV infected people. We verified participants ART adherence with their records in the ART center to reduce the potential desirability of reporting and recall biases. However, we did not execute the pill count measure.

There were some limitations in this study. First, participants were not blinded to the intervention. However, a rigorous coding system ensuring the anonymity was used with enumerator for data collection, entry and analysis. Second, reduced risky sexual behavior, high adherence and disclosure rate found in this study could be due to the Hawthorne effect (benefit of trial participation in the intervention group), which can eliminate the power to detect a factual difference from a trial [63]. Drug toxicity, accessibility and attitude might be potential confounders for adherence to ART. Further, these changes might have happened due to social desirability bias. However, a good rapport building during the intervention and data collection, familiar enumerator and study settings to participants all helped to reduce this bias. Third, a randomized controlled trial is a dynamic design that can reduce bias due to confounding. However, there are inbuilt biases that might be mostly pertinent in behavioral intervention trials. Factors such as process of informed consent, study measurement tools that are used many times and reimbursement for participation in the trial could add to changes in behaviors among both control and intervention groups. Fourth, this empowerment intervention did not cover economic aspects. Finally, factor analysis was not used due to sampling inadequacy. However, after face validity and few modifications to language, the reliability was tested and showed good internal consistency. In other settings when empowerment measurement tool will be applied, the validity and reliability should be evaluated before use in different local cultures and contexts.

\section{Conclusion}

The efficacy on empowerment of HIV infected people using ART was shown after receiving the intervention. Their risky sexual behaviors were reduced and their adherence to ART and disclosure of HIV were increased. The intervention contents can be utilized in regular services and its effectiveness needs to be evaluated after routine implementation. Further, the empowerment intervention framework and method of measurement 
can be used in different settings after validating its cultural and contextual acceptability and applicability.

\section{Abbreviations}

ART, antiretroviral therapy; DiD, Difference-in-Differences; HIV, human immunodeficiency virus; IQR, inter quartile range; NCASC, National Center for AIDS and STD Control; SD, standard deviation; STIDH, Sukraraj Tropical and Infectious Disease Hospital; USD, United States Dollar

\section{Acknowledgments}

This study was a part of the thesis of the first author for fulfilling the requirements of a PhD degree in Epidemiology at Prince of Songkla University, Thailand which is partially supported by the "Discipline of Excellencein Epidemiology (phase 2): Asia Mentoring Institute in Research". We thank the participants who volunteered to participate in this study. We also thank staff of the ART center for their help, regular support and coordination. We also thank E. Sally Rogers, ScD, Director of Research and Research Associate Professor, Center for Psychiatric Rehabilitation, Boston University for her support to provide the empowerment measurement tools. The final manuscript was edited by Mr. Edward McNeil.

\section{Funding}

This study was funded by Graduate School, Prince of Songkla University, Thailand (grant number 950/1538). The funder had no role in study design, data collection and analysis, decision to publish, or manuscript writing and was blind to whole study.

\section{Availability of data and materials}

All data supporting our findings is contained within the manuscript and the authors can be contacted at dnbhatta@yahoo.com (DNB) for further clarification if required.

\section{Authors' contributions}

DNB designed the intervention package and conceptualized the study, designed the protocol, coordinated and managed all the aspects of study procedures, reviewed study data, analyzed and interpreted the data, and drafted the manuscript. TL participated in designing the protocol, advised on design and study, reviewed study data, and reviewed and edited the final manuscript. Both authors read and approved the final manuscript.

\section{Competing interests}

The authors declare that they have no competing interests.

\section{Consent for publication}

Not applicable.

\section{Ethics approval and consent to participate}

\section{This project was approved by the Research Ethics Committee, Faculty of} Medicine, Prince of Songkla University, Thailand (reference no. 57-0146-18-5) and approved by Institutional Ethical Review Committee of Sukraraj Tropical and Infectious Disease Hospital (STIDH), Nepal (063/071/72) prior to study initiation. The trial was registered through trial registration number TCTR20140814002 (www.clinicaltrials.in.th). The participants were informed about the objectives and the method of the study and written informed consent was obtained from all participants prior to enrollment. Strict anonymity and confidentiality was maintained throughout the recruitment, intervention and data collection process.

\section{Received: 3 December 2015 Accepted: 7 June 2016}

\section{Published online: 10 June 2016}

\section{References}

1. Naghavi M, Wang H, Lozano R, Davis A, Liang X, Zhou M, et al. Global, regional, and national age-sex specific all-cause and cause-specific mortality for 240 causes of death, 1990-2013: a systematic analysis for the Global Burden of Disease Study 2013. Lancet. 2015;385(9963):117-71.

2. Vos T, Barber RM, Bell B, Bertozzi-Villa A, Biryukov S, Bolliger I, et al. Global, regional, and national incidence, prevalence, and years lived with disability for 301 acute and chronic diseases and injuries in 188 countries, 1990-2013: a systematic analysis for the Global Burden of Disease Study 2013. Lancet. 2015;386(9995):743-800.
3. Skarbinski J, Rosenberg E, Paz-Bailey G, Hall HI, Rose CE, Viall AH, et al. Human immunodeficiency virus transmission at each step of the care continuum in the United States. JAMA Internal Medicine. 2015;175(4):588-96.

4. WHO. Global summary of the HIV/AIDS epidemic, December 2014. Geneva: World Health Organization, HIV/AIDS Department; 2015.

5. Wilson DP, Law MG, Grulich AE, Cooper DA, Kaldor JM. Relation between HIV viral load and infectiousness: a model-based analysis. The Lancet. 2008; 372(9635):314-20.

6. Gardner EM, McLees MP, Steiner JF, del Rio C, Burman WJ. The spectrum of engagement in HIV care and its relevance to test-and-treat strategies for prevention of HIV infection. Clin Infect Dis. 2011;52(6):793-800.

7. Hall HI, Frazier EL, Rhodes P, Holtgrave DR, Furlow-Parmley C, Tang T, et al. Differences in human immunodeficiency virus care and treatment among subpopulations in the United States. JAMA Internal Medicine. 2013;173(14):1337-44.

8. Hughes JP, Baeten JM, Lingappa JR, Magaret AS, Wald A, de Bruyn G, et al. Determinants of per-coital-act HIV-1 infectivity among African HIV-1serodiscordant couples. J Infect Dis. 2012;205(3):358-65.

9. Quinn T, Wawer M, Sewankambo N, Serwadda D, Li C, Wabwire-Mangen F, et al. Rakai Project Study Group Viral load and heterosexual transmission of human immunodeficiency virus type 1. N Engl J Med. 2000;342(13):921-9.

10. Mizuno Y, Zhu J, Crepaz N, Beer L, Purcell DW, Johnson CH, et al. Receipt of HIV/STD prevention counseling by HIV-infected adults receiving medical care in the United States. AIDS. 2014;28(3):407-15.

11. Hall HI, Holtgrave DR, Maulsby C. HIV transmission rates from persons living with HIV who are aware and unaware of their infection. AIDS. 2012;26(7):893-6.

12. Marks G, Crepaz N, Janssen RS. Estimating sexual transmission of HIV from persons aware and unaware that they are infected with the virus in the USA. AIDS. 2006;20(10):1447-50.

13. Cohen MS, Chen YQ, McCauley M, Gamble T, Hosseinipour MC, Kumarasamy N, et al. Prevention of HIV-1 infection with early antiretroviral therapy. N Engl J Med. 2011;365(6):493-505.

14. UNAIDS. Treatment 2015. Joint United Nations Programme on HIV/AIDS (UNAIDS), Geneva, Switzerland. 2015. http://wwwunaidsorg/sites/default/ files/media_asset/JC2484_treatment-2015_en_1 pdf. Accessed 14 June 2015.

15. Laurent C, Gueye NFN, Ndour CT, Gueye PM, Diouf M, Diakhaté N, et al. Long-term benefits of highly active antiretroviral therapy in Senegalese HIV1-infected adults. J Acquir Immune Defic Syndr. 2005;38(1):14-7.

16. Lohse N, Hansen A-BE, Pedersen G, Kronborg G, Gerstoft J, Sørensen HT, et al. Survival of persons with and without HIV infection in Denmark, 19952005. Ann Intern Med. 2007;146(2):87-95.

17. Stringer JS, Zulu I, Levy J, Stringer EM, Mwango A, Chi BH, et al. Rapid scaleup of antiretroviral therapy at primary care sites in Zambia: feasibility and early outcomes. JAMA. 2006;296(7):782-93.

18. Quinlivan EB, Messer LC, Adimora AA, Roytburd K, Bowditch N, Parnell H, et al. Experiences with HIV testing, entry, and engagement in care by HIVinfected women of color, and the need for autonomy, competency, and relatedness. AIDS Patient Care STDs. 2013;27(7):408-15.

19. Van Devanter N, Duncan A, Birnbaum J, Burrell-Piggott T, Siegel K. Gender power inequality and continued sexual risk behavior among racial/ethnic minority adolescent and young adult women Living with HIV. J AIDS \& Clinical Res. 2011;(0):003

20. Brothers J, Harper GW, Fernandez MI, Hosek SG, The Adolescent Trials Network for HIV/AIDS Interventions. EVOLUTION-Taking Charge and Growing Stronger: The Design, Acceptability, and Feasibility of a Secondary Prevention Empowerment Intervention for Young Women Living with HIV. AIDS Patient Care STDs. 2014;28(1):33-42.

21. Fisher JD, Smith L. Secondary prevention of HIV infection: the current state of prevention for positives. Curr Opin HIV AIDS. 2009;4(4):279-87.

22. Gutiérrez L, Oh HJ, Gillmore MR. Toward an understanding of (em) power (ment) for HIV/AIDS prevention with adolescent women. Sex Roles. 2000;42(7-8):581-611.

23. Hosek S, Brothers J, Lemos D, The Adolescent Medicine Trials Network for HIV/AIDS Interventions. What HIV-positive young women want from behavioral interventions: A qualitative approach. AIDS Patient Care STDs. 2012;26(5):291-7.

24. Rotheram-Borus MJ, Swendeman D, Lee S-J, Li L, Amani B, Nartey M. Interventions for families affected by HIV. Translational behavioral medicine. 2011;1(2):313-26.

25. UKAID. Towards zero infections: the UK's position paper on HIV in the developing world. UK: Department for International Development; 2011. 
26. UNAIDS. Getting to zero: 2011-2015 strategy. Joint United Nations Programme on HIV/AIDS. Geneva, Switzerland: UNAIDS; 2010.

27. USAID. Global Health Programs: Progress Report to Congress FY 2012. Washington, DC: USAID; 2013.

28. Hermann K, Van Damme W, Pariyo GW, Schouten E, Assefa Y, Cirera A, et al. Community health workers for ART in sub-Saharan Africa: learning from experience-capitalizing on new opportunities. Hum Resour Health. 2009;7:31.

29. Kerrigan DL, Fonner VA, Stromdahl S, Kennedy CE. Community empowerment among female sex workers is an effective HIV prevention intervention: a systematic review of the peer-reviewed evidence from lowand middle-income countries. AIDS Behavior. 2013;17(6):1926-40.

30. Kober K, Van Damme W. Scaling up access to antiretroviral treatment in southern Africa: who will do the job? Lancet. 2004;364(9428):103-7.

31. Stein J, Lewin S, Fairall L, Mayers P, English R, Bheekie A, et al. Building capacity for antiretroviral delivery in South Africa: a qualitative evaluation of the PALSA PLUS nurse training programme. BMC Health Serv Res. 2008;8(1):240.

32. Pan SC, Tien $\mathrm{KL}$, Hung IC, Lin YJ, Yang YL, Yang MC, et al. Patient empowerment in a hand hygiene program: Differing points of view between patients/family members and health care workers in Asian culture. Am J Infect Control. 2013;41(11):979-83.

33. Leerlooijer JN, Bos AE, Ruiter RA, van Reeuwijk MA, Rijsdijk LE, Nshakira N, et al. Qualitative evaluation of the Teenage Mothers Project in Uganda: a community-based empowerment intervention for unmarried teenage mothers. BMC Public Health. 2013;13(1):816.

34. Kerrigan D, Wirtz A, Baral S, Stanciole A, Butler J, Oelrichs R et al. The global HIV epidemics among sex workers. Washington DC: World Bank Publications; 2012.

35. Vassall A, Chandrashekar S, Pickles M, Beattie TS, Shetty G, Bhattacharjee P, et al. Community Mobilisation and Empowerment Interventions as Part of HIV Prevention for Female Sex Workers in Southern India: A CostEffectiveness Analysis. 2014.

36. Rogers EM. A prospective and retrospective look at the diffusion model. J Health Commun. 2004;9(S1):13-9.

37. Bandura A. Social-learning theory of identificatory processes. Handbook of socialization theory and research. Chapter 3. Chicago: Rand McNally \& company; 1969. p. 213-62.

38. Bandura A, McClelland DC. Social learning theory. Englewood Cliffs, NJ: Prentice-Hall; 1977

39. Ewart CK. Social action theory for a public health psychology. Am Psychol. 1991;46(9):931-46.

40. Zimmerman MA. Psychological empowerment: Issues and illustrations. Am J Community Psychol. 1995;23(5):581-99.

41. Zimmerman MA, Rappaport J. Citizen participation, perceived control, and psychological empowerment. Am J Community Psychol. 1988;16(5):725-50.

42. Freire P. Pedagogy of the oppressed. New York: Continuum International Publishing Group; 2000.

43. Gutierrez LM. Working with women of color: An empowerment perspective. Soc Work. 1990;35(2):149-53.

44. NCASC. Factsheet N4: Antiretroviral Therapy (ART) services in Nepal. Ministry of Health, Government of Nepal, Kathmandu. Kathmandu, Nepal: National Centre for AIDS and STD Control; 2011.

45. NCASC. Fact sheets on HIV and AIDS. Misintry of Health, Government of Nepal, Kathmandu. Kathmandu, Nepal: National Center for AIDS and STD Control; 2014.

46. NCASC. National Guidelines for Antiretroviral Therapy. Misnitry of Health, Government of Nepal, Kathmandu. Kathmandu, Nepal: National Centre for AIDS and STD Control; 2012.

47. Rogers ES, Chamberlin J, Ellison ML, Crean T. A consumer-constructed scale to measure empowerment among users of mental health services. Psychiatr Serv. 1997;48(8):1042-7.

48. Ashenfelter O, Card D. Using the longitudinal structure of earnings to estimate the effect of training programs. The Review of Economics and Statistics. 1985;67(4):648-660.

49. Khandker SR, Koolwal GB, Samad HA. Handbook on impact evaluation: quantitative methods and practices. Washington DC: World Bank Publications; 2010

50. Villa JM. DIFF: Stata module to perform Differences in Differences estimation. Stat Softw Components. 2014.

51. NHS. Code of Confidentiality. http://webarchive.nationalarchives.gov. uk/20130107105354/http://www.dh.gov.uk/prod_consum_dh/groups/ dh_digitalassets/@dh/@en/documents/digitalasset/dh_4069254.pdf. Accessed 13 June 2014.
52. Côté J, Godin G, Ramirez-Garcia P, Rouleau G, Bourbonnais A, Guéhéneuc Y$\mathrm{G}$, et al. Virtual Intervention to Support Self-Management of Antiretroviral Therapy Among People Living With HIV. J Med Internet Res. 2015;17(1):e6.

53. Li L, Ji G, Liang LJ, Ding Y, Tian J, Xiao Y. A multilevel intervention for HIVaffected families in China: Together for Empowerment Activities (TEA). Soc Sci Med. 2011;73(8):1214-21.

54. Nakimuli-Mpungu E, Wamala K, Okello J, Alderman S, Odokonyero R, Mojtabai R, et al. Group support psychotherapy for depression treatment in people with HIV/AIDS in northern Uganda: a single-centre randomised controlled trial. The Lancet HIV. 2015;2(5):e190-9.

55. Rotheram-Borus MJ, Swendeman D, Comulada WS, Weiss RE, Lee M, Lightfoot M. Prevention for substance-using HIV-positive young people: telephone and in-person delivery. J Acquir Immune Defic Syndr. 2004;37 Suppl 2:S68-77.

56. Wu L, Li X. Community-based HIV/AIDS interventions to promote psychosocial well-being among people living with HIV/AIDS: a literature review. Health Psychology and Behavioral Medicine: An Open Access Journal. 2013;1(1):31-46.

57. Ironson $\mathrm{GH}, \mathrm{Hs} \mathrm{H}$. Do positive psychosocial factors predict disease progression in HIV-1? A review of the evidence. Psychosom Med. 2008;70(5):546.

58. Crepaz N, Tungol-Ashmon MV, Higa DH, Vosburgh W, Mullins MM, Barham T, et al. A systematic review of interventions for reducing HIV risk behaviors among people living with HIV in the United States, 1988-2012. AIDS. 2014;28(5):633-56.

59. Kerrigan D, Kennedy CE, Morgan-Thomas R, Reza-Paul S, Mwangi P, Win KT, et al. A community empowerment approach to the HIV response among sex workers: effectiveness, challenges, and considerations for implementation and scale-up. Lancet. 2015;385(9963):172-85.

60. Kaihin R, Kasatpibal N, Chitreechuer J, Grimes RM. Effect of an empowerment intervention on antiretroviral drug adherence in Thai Youth. Behavioral Medicine. 2015;41(4):186-194.

61. Mayfield Arnold E, Rice E, Flannery D, Rotheram-Borus MJ. HIV disclosure among adults living with HIV. AIDS Care. 2008;20(1):80-92.

62. Bhatta DN, Liabsuetrakul T. Design and feasibility of a social self-value intervention package to empower people living with HIV. AIDS Care. 2016;7-14.

63. McCambridge J, Witton J, Elbourne DR. Systematic review of the Hawthorne effect: new concepts are needed to study research participation effects. J Clin Epidemiol. 2014;67(3):267-77.

\section{Submit your next manuscript to BioMed Central and we will help you at every step:}

- We accept pre-submission inquiries

- Our selector tool helps you to find the most relevant journal

- We provide round the clock customer support

- Convenient online submission

- Thorough peer review

- Inclusion in PubMed and all major indexing services

- Maximum visibility for your research

Submit your manuscript at www.biomedcentral.com/submit 